\title{
Molecular Modeling Study of Quercetin and their Metal Complexes
}

\author{
M. Rajendran \\ Associate Professor \\ Research and Postgraduate \\ Department of Chemistry, \\ N.M.S.S.Vellaichamy Nadar \\ College, Nagamalai, Madurai \\ 625 019, Tamilnadu, India.
}

\author{
R. Ravichandran \\ Research and Postgraduate \\ Department of Chemistry, \\ N.M.S.S.Vellaichamy Nadar \\ College, Nagamalai, Madurai \\ 625 019, Tamilnadu, India.
}

\author{
D. Devapiriam \\ Associate Professor \\ Research and Postgraduate \\ Department of Chemistry, \\ N.M.S.S.Vellaichamy Nadar \\ College, Nagamalai, Madurai \\ 625 019, Tamilnadu, India.
}

\begin{abstract}
A chemical behavior of Quercetin as antioxidant and metal chelator has become the subject of intense experimental research. In this paper, we apply a semi empirical approach to study the stability constant of Quercetin with metals like Cd, $\mathrm{Pb}$ and $\mathrm{Bi}$. The comparative analysis of the theoretical formation constant of Quercetin-metal complexes with metals with experimental results shows that $\mathrm{H}$-removal from phenolic -OH site during the metal chelation correlated with experimentally determined stability constant by Job's method. The analysis of the theoretical BDE (Bond Dissociation Energy) values, for all $\mathrm{OH}$ sites in Quercetin, clearly shows the importance of the B-ring $-\mathrm{OH}$ groups. Mulliken spin density distribution for the radicals formed after H-removal on each $\mathrm{OH}$ site of Quercetin is also investigated. The results indicate that 3'-O' and 4'-O' (B-ring) Quercetin radical spin density appears to be more delocalized than the other sites present on A-ring.
\end{abstract}

\section{Keywords}

Quercetin, semi-empirical, metal chelation, stability constant, Arguslab 4.0.

\section{INTRODUCTION}

Quercetin is one of the most abundant flavonoids in vegetable tissues and present high antioxidant activity. Besides, flavonoids may inhibit the generation of primary oxygen radicals and the following chain oxidation, being effective chelators of transition metal ions [1]. The antioxidant activity of flavonoids is related to the chelation of metal ions, which catalyse the production of hydroxyl and lipid radicals through the decomposition of preformed lipid hydroperoxides [2, 3]. In particular, iron and copper ions play a major role in the production of the very reactive hydroxyl radical (HO) through Fenton and Haber-Weiss reactions [4, 5]. Chelation of these ions with flavonoids may be a natural way to reduce or eliminate their undesirable catalytic behavior, in fact, metalflavonoid complexes may be a preferred way of ion chelation as compared to synthetic chelator that can pose toxicity problems [6]. Chelation potency of flavonoids is mainly related to the presence of catechol moiety in the $\mathrm{B}$ ring $[7,8]$ while redox behavior of ligands in complexes depends on the presence of the 3-hydroxy group in their structure [8].

The complexation with metal ions decreases the oxidation potential of the flavonoids/semiquinone redox pair. As a consequence, the complexed flavonoids are relatively more readily oxidized by superoxide ion than the uncomplexed ones [9]. The cyclic voltammetric data also shows a considerable decrease of the oxidation potentials of the complexes related to that of the free flavonoids. Thus flavonoid-metal complexes have been found to be more effective antioxidant than the free flavonoids [9].

Flavonoids are characterized by the presence of an $\mathrm{OH}$ group at C-3. The absence of this group (i.e. flavones) induces a significant blue shift. This can be directly attributed to partial loss of $\pi$-conjugation in flavones. The glycosylation of the 3 $\mathrm{OH}$ group of flavonoids (from quercetin to rutin) also induces a hypsochromic shift. This can be attributed to a decrease in the HOMO - LUMO gap [20]. Quercetin was thus investigated as a basis compound, which should be more appropriate candidate, due to the larger conjugated backbone. Due to the excessive computation time required for DFT calculations of BDE of flavonoids, we calculated BDE by semi-empirical methods (molecular mechanics, UFF). We used Quercetin, the most investigated flavonoids and its metal complexes by quantum chemical calculations for this study. The aim of the present work is to investigate the complexation of $\mathrm{Cd}, \mathrm{Pb}$ and $\mathrm{Bi}$ metal ions with Quercetin using semiempirical method. These theoretical results are compared with the stability constant data determined through Job's method. These theoretical predictions explain the formation of Quercetin-metal complexes and are useful in elucidating the complexation mechanism and antioxidant activity of Quercetin [10, 11]. In this paper, the results of BDE calculations, HOMO, LUMO and Mulliken spin density distribution values in the radical species are examined. The structure activity relationships are discussed mainly focusing the reactivity of $\mathrm{OH}$ groups in Quercetin and the radical formed after the $\mathrm{H}$ - removal from this molecule.

\section{MATERIALS AND METHODS}

All conformational analysis (geometry optimization) study was performed on window based Arguslab 4.0 software [12]. The Quercetin structure is generated by Arguslab and optimization was performed with the semi-empirical AM1 parameterization (Fig. 1) [13]. Geometry optimization was performed by molecular mechanics (UFF) method, for the optimized structure of the parent molecule and the radicals formed after the removal of $\mathrm{H}$-atom from the 3, 5, 7, 3' or 4' position. No geometrical parameter constraint was imposed during the optimization.

\section{RESULTS AND DISCUSSION}

Table 1 show the optimized heat of formation of metal chelated quercetin complexes, which are taken after geometry optimization of metal chelated quercetin metal complex from Arguslab by using molecular mechanics calculation. In alkaline medium phenolic - $\mathrm{OH}$ group will be modified to phenolate anion, hence in this complex construction $-\mathrm{H}$ atom 
is removed during the complex structure formation. Table 1 results shows that formation constant of the quercetin metal complex is in the following order $\mathrm{Q}-\mathrm{Pb}>\mathrm{Q}-\mathrm{Cd}>\mathrm{Q}-\mathrm{Bi}$.
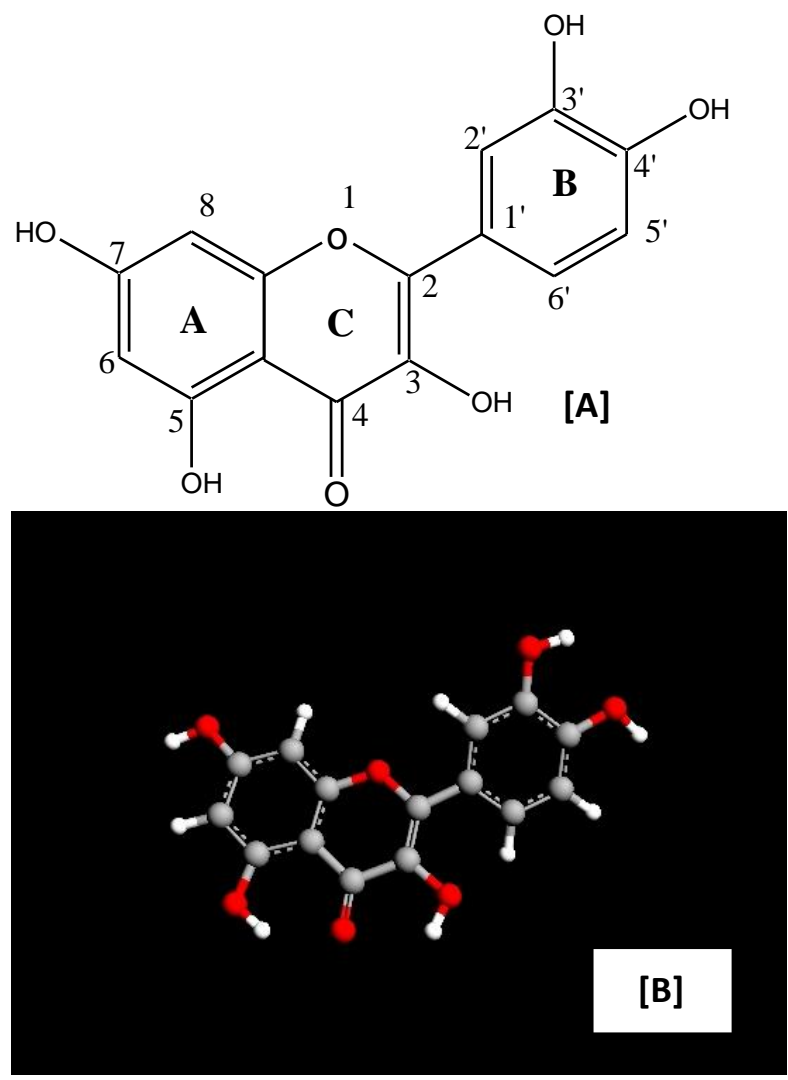

Fig. 1 (A) Chemical structure of Quercetin, (B) the AM1 optimized structure of Quercetin.

The formation constant of metal-Quercetin complexes were studied in acidic media assuming to have proton in the $-\mathrm{OH}$ functional group during the complex formation. Hence, the formation constant study of Q-metal complex structures are optimized keeping the proton in the $-\mathrm{OH}$ functional group and these results are shown in the Table 2. The optimization of Quercetin-metal complex is carried out by molecular mechanics calculation. The formation constant of Quercetinmetal complex has the following order $\mathrm{Q}-\mathrm{Pb}>\mathrm{Q}-\mathrm{Cd}>\mathrm{Q}-$ $\mathrm{Bi}$. The formation constant values reported in Table 1 and 2 are exhibiting similar trend. The analysis of the results from Table 1 and 2 has shown that metal chelation carried out either in 3-OH and 4-keto group or in 5-OH and 4-Keto group or in 3'-OH and 4'-OH catechol group, the formation constant of the complex follows the same order.

The stability constant of the Quercetin-metal complexes are experimentally studied in two different $\mathrm{pH}$ condtions $(\mathrm{pH}=$ 4.4 and $\mathrm{pH}=7.4$ ) by Job's method. The mole fraction studies of Quercetin with metals show that the ratio of Quercetin and metal in a complex is identified as 1:1. The experimentally measured stability constant of Quercetin-metal complexes are listed in Table 3 . This table shows that the stability constant values are in the order of $\mathrm{Q}-\mathrm{Pb}>\mathrm{Q}-\mathrm{Cd}>\mathrm{Q}-\mathrm{Bi}$ at $\mathrm{pH}=7.4$, while at the $\mathrm{pH}=4.4$ the stability constant values are in the order of $\mathrm{Q}-\mathrm{Cd}>\mathrm{Q}-\mathrm{Pb}>\mathrm{Q}-\mathrm{Bi}$.

The stability constant measured by Job's method at $\mathrm{pH}=7.4$ agrees with the results of theoretically calculated results. Stability constant measured at $\mathrm{pH}=4.4$ does not correlate with the theoretically calculated results. This may be explained by the existence of phenolate anion during the Quercetin-metal complex formation.

\subsection{Bond dissociation energy}

The phenolic $-\mathrm{OH}$ bond dissociation energies calculated by molecular mechanics are presented in the Table 4 . The ability of flavonoid antioxidants to donate a hydrogen atom is mainly governed by the BDE value of $\mathrm{O}-\mathrm{H}$ bond. The BDE of $\mathrm{OH}$ bond can be calculated by the following equation [15].

$$
\mathrm{BDE}(\mathrm{Fl}-\mathrm{OH})=\Delta_{\mathrm{f}} \mathrm{H}\left(\mathrm{Fl}-\mathrm{O}^{*}\right)+\Delta_{\mathrm{f}} \mathrm{H}(\mathrm{H})-\Delta_{\mathrm{f}} \mathrm{H}(\mathrm{Fl}-\mathrm{OH})
$$

flavonoid phenoxyl radical generated after $\mathrm{H}^{\cdot}$ abstraction, $\Delta_{\mathrm{f}} \mathrm{H}$ $(\mathrm{H})$ is the enthalpy of formation of the hydrogen atom and $\Delta_{\mathrm{f}} \mathrm{H}(\mathrm{Fl}-\mathrm{OH})$ is the enthalpy of formation of the parent flavonoid molecule. The larger values of BDE obtained for 3$\mathrm{OH}$ and 5-OH may be attributed to the involvement of $4^{\text {th }}$ keto group in hydrogen bonding with 3 and 4-OH groups.

From the current knowledge of the radical scavenging processes of flavonoid antioxidants, it is noted that the singlestep hydrogen atom transfer seems to be the simplest mechanism [14]. The product of this mechanism is a stable flavonoid phenoxyl radical (Fl-O). The hydrogen donating ability of flavonoids to scavenge free radical can be characterized by the bond dissociation energy (BDE) of $\mathrm{OH}$ bond [15]. The BDE value of the $\mathrm{OH}$ bond is an important parameter in evaluating the antiradical action, because the weaker the $\mathrm{O}-\mathrm{H}$ bond the faster the radical inactivation. In general, intramolecular hydrogen bonds, expanded electron delocalization, and resonance stabilization contribute to the stability of Fl-O [16].

The minimal value of the BDE of $\mathrm{O}-\mathrm{H}$ bonds indicates which $\mathrm{O}-\mathrm{H}$ group on the flavonoid core posses the most abstractable hydrogen, that is, which $\mathrm{O}-\mathrm{H}$ group is targeted for radical attack. The BDE values of $\mathrm{OH}$ bonds of quercetin have been calculated by several research groups using different chemical methods [17]. Table 4 shows the BDE values of $\mathrm{O}-\mathrm{H}$ in the various positions. 
Table 1 Formation constant values of Quercetin and metal complexes. The complexes are optimized with molecular mechanics (UFF), without phenolic hydrogen atom.

\begin{tabular}{|c|c|c|c|c|}
\hline S.NO. & $\begin{array}{c}\text { Quercetin-metal } \\
\text { complex }\end{array}$ & $\begin{array}{c}4 \mathrm{C}=\mathrm{O} \text { and } \\
3-\mathrm{OH} \\
\mathrm{Kcal} / \mathrm{mol}\end{array}$ & $\begin{array}{c}3^{\prime}-\mathrm{OH} \text { and } \\
4{ }^{\prime}-\mathrm{OH} \\
\mathrm{Kcal} / \mathrm{mol}\end{array}$ & $\begin{array}{c}4 \mathrm{C}=\mathrm{O} \text { and } \\
5-\mathrm{OH} \\
\mathrm{Kcal} / \mathrm{mol}\end{array}$ \\
\hline 1 & Quercetin-Cadmium & 78.1829 & 76.3619 & 74.6482 \\
\hline 2 & Quercetin-Lead & 79.1154 & 77.6039 & 78.1535 \\
\hline 3 & Quercetin-Bismuth & 69.0483 & 72.7888 & 71.0343 \\
\hline
\end{tabular}

Table 2 Formation constant values of Quercetin and metal complexes. The complexes are optimized with molecular mechanics (UFF), with phenolic hydrogen atom.

\begin{tabular}{|c|c|c|c|c|}
\hline S.NO. & Quercetin-metal complex & $\begin{array}{c}4 \mathrm{C}=\mathrm{O} \text { and } \\
3-\mathrm{OH} \\
\mathrm{Kcal} / \mathrm{mol}\end{array}$ & $\begin{array}{c}\text { 3'-OH }^{\prime} \text { and } \\
4{ }^{\prime}-\mathrm{O} \\
\mathrm{Kcal} / \mathrm{mol}\end{array}$ & $\begin{array}{c}4 \mathrm{C}=\mathrm{O} \text { and } \\
5-\mathrm{OH} \\
\mathrm{Kcal} / \mathrm{mol}\end{array}$ \\
\hline 1 & & 74.4024 & 72.1479 & 74.3651 \\
\hline 2 & Quercetin-Cadmium & 75.4170 & 73.6529 & 78.2731 \\
\hline 3 & Quercetin-Lead & 65.4957 & 63.6415 & 72.4496 \\
\hline
\end{tabular}

Table 3 Stability constant of Quercetin metal complexes determined by Job's method (Unpublished data).

\begin{tabular}{|c|c|c|c|}
\hline $\mathrm{pH}$ & Quercetin-Cadmium & Quercetin-Lead & Quercetin-Bismuth \\
\hline 4.4 & $2.27 \times 10^{6}$ & $1.49 \times 10^{6}$ & $4.47 \times 10^{4}$ \\
\hline 7.4 & $7.80 \times 10^{6}$ & $9.00 \times 10^{6}$ & $2.54 \times 10^{4}$ \\
\hline
\end{tabular}

Table 4 Quercetin -OH Bond Dissociation Energies (in Kcal/mol). Quercetin optimized with molecular mechanics (UFF).

\begin{tabular}{|c|c|c|c|c|c|}
\hline S.NO. & $7-\mathrm{OH}$ & $5-\mathrm{OH}$ & $3-\mathrm{OH}$ & $3^{\prime}$ '-OH & $4^{\prime}-\mathrm{OH}$ \\
\hline 1 & 14.1714 & 26.0838 & 17.4037 & 16.2887 & 14.3604 \\
\hline
\end{tabular}

Table 5 Mulliken spin density of atoms in Quercetin, after removal of hydrogen from -OH species.

\begin{tabular}{|c|c|c|c|c|c|c|c|c|c|}
\hline Quercetin & $1-\mathrm{O}$ & $2-\mathrm{C}$ & $3-\mathrm{C}$ & $3-\mathrm{O}$ & $4=\mathrm{O}$ & $5-\mathrm{O}$ & $7-\mathrm{O}$ & $3^{\prime}-\mathrm{O}$ & $4^{\prime}-\mathrm{O}$ \\
\hline Querc. Free & $\mathbf{- 0 . 5 8 6}$ & $\mathbf{0 . 2 4 6}$ & $\mathbf{0 . 2 2 7}$ & $\mathbf{- 0 . 6 6 8}$ & $\mathbf{- 0 . 3 9 9}$ & $\mathbf{- 0 . 6 0 2}$ & $\mathbf{- 0 . 6 3 9}$ & $\mathbf{- 0 . 6 1 4}$ & $\mathbf{- 0 . 6 1 1}$ \\
\hline $3-\mathrm{O}$ & -0.587 & 0.227 & 0.298 & $\mathbf{- 0 . 4 4 1}$ & -0.390 & -0.598 & -0.636 & -0.611 & -0.608 \\
\hline $5-\mathrm{O}$ & -0.583 & 0.248 & 0.225 & -0.665 & -0.372 & $\mathbf{- 0 . 3 7 0}$ & -0.632 & -0.611 & -0.608 \\
\hline $7-\mathrm{O}$ & -0.581 & 0.247 & 0.228 & 0.666 & -0.395 & -0.595 & $\mathbf{- 0 . 4 1 4}$ & -0.610 & -0.608 \\
\hline 3 '-O & -0.584 & 0.249 & 0.229 & -0.664 & -0.395 & -0.599 & -0.636 & $\mathbf{- 0 . 4 0 0}$ & -0.607 \\
\hline 4 '-O & -0.586 & 0.229 & 0.301 & -0.435 & -0.386 & -0.595 & -0.633 & -0.607 & $\mathbf{- 0 . 3 9 1}$ \\
\hline $\begin{array}{l}\text { Diff.in } \\
\text { spin } \\
\text { density }\end{array}$ & - & - & - & $\mathbf{- 0 . 2 2 7}$ & - & $\mathbf{- 0 . 2 3 2}$ & $\mathbf{- 0 . 2 2 5}$ & $\mathbf{- 0 . 2 1 4}$ & $\mathbf{- 0 . 2 2 0}$ \\
\hline
\end{tabular}


The energy order of the BDE of $\mathrm{OH}$ group is $7-\mathrm{OH}<4$ '-OH $<3$ '-OH $<3-\mathrm{OH}<5-\mathrm{OH}$. This indicates that except for $7-\mathrm{OH}$, all the results are in the same order as determined by DFT methods $[17,18]$. The $7-\mathrm{OH}$ group has lowest BDE than the other substituted $-\mathrm{OH}$ groups, this may be justified by considering that there is no chance for intramolecular hydrogen bond as in the positions $3,5,3$ ' or 4'. The earlier results have suggested that $\mathrm{BDE}$ is an excellent primary descriptor of the antioxidant activity. Even if no experimental data are available for comparison for flavonoids, these semiempirical results appear quite realistic for phenolic compounds.

Table 4 results show that $\mathrm{H}$-transfer from B-ring (4'-OH and 3'- $\mathrm{OH})$ is easier than from A ring $(5-\mathrm{OH})$. The BDE values for the $\mathrm{OH}$ in different sites on the A-ring are higher than those of B-ring. The present semi-empirical values clearly demonstrate that $\mathrm{H}$-transfer is more energetically favourable from the B-ring and that $\mathrm{H}$-transfer from 3-OH group (C-ring) is also possible in quercetin, depending on the oxidative system. BDE could serve as a theoretical measure for ranking flavonoids as antioxidants because most active flavonoids possess lower value of BDE. It is generally agreed upon that the major role in free radical scavenging is that of aromatic hydroxyl groups attached to flavonoid nuclei. It seems that $\mathrm{OH}$ groups of attached sugars, as well as hydrogen attached to flavonoid core do not contribute to scavenging potency [19]

\subsection{Mulliken atomic charges}

Importance of spin densities: The calculated BDE values of quercetin are often attributed to $\pi$-electron delocalization, which leads to the stabilization of the radicals obtained after $\mathrm{H}$-abstraction. In the unrestricted scheme, the spin density is often considered to be a more realistic parameter and provides a better representation of the reactivity [21]. Spin density of flavonoid has been an important factor in the description of antioxidant behavior [22]. Hence, we have decided to analyse the spin density on the various Quercetin radical, in order to analyse the reactivity of the $\mathrm{OH}$ sites in flavonoids and consequently the difference in $\mathrm{BDE}$.

Comparison of spin density value of $B$ and $A$ rings: The more delocalized the spin density in the radical, the easier is the radical formed and thus the lower the BDE is well documented in the earlier work [23]. The table 5 shows that the spin density appears to be slightly more delocalized for radicals formed from the B-ring (3'-OH and 4'-OH) than for those located on the A-ring (5-OH and 7-OH). Compared to free Quercetin the Quercetin radical has lower spin densities. The difference in spin density value of free Quercetin and Quercetin radical species are analysesd. The decrease in spin density value is 0.214 and 0.220 for $3^{\prime}-\mathrm{O}$ ' and 4'-O' radical species present in B-ring. This value is lower than that of A-ring 5-O' and 7-O' radical spin densities. This indicates that there is more delocalization, for oxygen radical formed from B-ring. The spin density value of oxygen radical for $3-\mathrm{O}$ and 5-O' (A-ring) is 0.227 and 0.232 respectively and this value is higher than B-ring oxygen radical. This may be due to the hydrogen bonding of $3 \& 5 \mathrm{OH}$ groups with the $4^{\text {th }}$ keto group oxygen. A lower spin density value of 0.225 is obtained for $7-\mathrm{O}^{-}$. This value is lower than the value of 5-O radical, and this may be due to the absence of involvement of any hydrogen bond in $\mathrm{OH}$ group at $7^{\text {th }}$ position.

Table 5 results show that the spin density on the C-2 atom and C-3 atom are almost similar for phenoxyl radical formed after $\mathrm{H}$-atom removed on the $\mathrm{OH}$ group of quercetin and free Quercetin. The amount of spin density present on C-2 and C-3 atoms imply high reactivity of that site. This leads to the conclusion that the higher antioxidant activity of quercetin is related to the presence of hydroxyl group and the 2,3-double bond which confers high reactivity to the $\mathrm{OH}$ sites.

\section{CONCLUSION}

The study of theoretical insight can contribute significantly to the understanding of the stability of the quercetin with different metals. We used semi empirical theoretical approach to confirm the experimentally determined results. As an extension of this work we are planning to study the same system with quantum mechanical, $a b$ initio and DFT methods with higher basis set, in order to predict the correlation percentage with experimental results.

\section{ACKNOWLEDGEMENTS}

This work was supported by the research grants from the UGC (University Grants Commission) major research project No.: F. No. 39-731/2010 (SR) Government of India. The corresponding author (MR) is grateful to UGC (New Delhi) for providing financial assistance. The authors are thankful to principal and the management of N.M.S.S. Vellaichamy Nadar College for providing laboratory facilities.

\section{REFERENCES}

[1] Afana's ev, I.B.; Dorozhko, A.I.; Brodskii, A.V.; Kostyuk, V.A.; Potapovitch, A.I. Chelating and free radical scavenging mechanisms of inhibitory action of rutin and quercetin in lipid peroxidation. Bichem. Pharmacol. 1989, 38, 1763-1769.

[2 McCord, J.M.; Day. E.D. Superoxide-dependent production of hydroxyl radical catalyzed by iron-EDTA complex. Jr., FEBS Lett. 1978, 86, 139-142.

[3] Halliwell, B. Superoxide-dependent formation of hydroxyl radicals in the presence of iron chelates: Is it a mechanism for hydroxyl radical production in biochemical systems? FEBS Lett. 1978, 92, 321-326.

[4] Fernandez, M.T.; Mira, M.L.; Florencio, M.H.; Jennings, K.R. Iron and copper chelation by flavonoids: an electrospray mass spectrometry study J. Inorg. Biochem. 2002, 92, 105-111.

[5] Mira, L.; Fernandez, M.T.; Santos, M.; Rocha, R.; Florenchio, M.H.; Jennings, K.R. Interactions of flavonoids with iron and copper ions: a mechanism for their antioxidant activity. Free Radical Res. 2002, 36, 1199-1208.

[6] Aruoma, O. Characterization of drugs as antioxidant prophylactics Free Radical Biol. Med. 1996, 20, 675705.

[7] De Souza, R.F. V.; Sussuchi, E.M.; De Giovani, W.F. Synthesis and Reactivity in inorganic and metal-organic chemistry. Met. Org. Chem. 2003, 33, 1125.

[8] Brown, J.E.; Khodr, H.; Hider, R.; Rice-Evans, C.A. Structural dependence of flavonoid interactions with $\mathrm{Cu}^{2+}$ ions: implications for their antioxidant properties. Biochem.J. 1998, 330, 1173-1178.

[9] Pietta, P.G. Flavonoids as antioxidants. J. Nat. Prod. 2000, 63, 1035-1042. 
[10] Eswaramoorthy, S.; Kumaran, D.; Keller, Role of metals in the biological activity of Clostridium botulinum neurotoxins. J. Biochemistry. 2004, 43, 2209-2216.

[11] Hermes-Lima, M.; Ponka, P.; Schulman, H.M. The iron chelator pyridoxal isonicotinoyl hydrazone $(\mathrm{PIH})$ and its analogues prevent damage to 2-deoxyribose mediated by ferric iron plus ascorbate Biochim. Biophys. Acta (BBA) General subjects. 2000, 1523, 154-160.

[12] Thompson, M.A. (2005) 4.0.1 ed.; Planaria Software LLC: Seattle.

[13] Dewar, M.J.S.; Zoobisch, E.G.; Healy E.F.; Stewart, J.J.P. AM1: A new general purpose quantum mechanical molecular model. J. Am.Chem. Soc. 1073 (1985) 3902-3909.

[14] Tsimidou, M.Z.; Nenadis, N.; Zhang, H-Y. In antioxidant plant phenols. Sources, Structure-Activity Relationship, Current Trends in Analysis and Characterization; D. Boskou, I. Gerothanasis, P. Kefalas, Eds.; Research Signpost: Kerala. (2006) 29.

[15] Wright, J.S.; Johnson, E.R.; Dilabio, G.A. Predicting the activity of phenolic antioxidants: theoretical method, analysis of substituent effects, and application to major families of antioxidants. J. Am. Chem. Soc. 2001, 123, 1173-1183.

[16] Bors, W.; Heller, W.; Mihel, C.; Saran, M. In Methods in Enzymology; Packer, L. Glazer, A.N. Eds.; Academic Press; San Diego.1990, 186, 343 -355.
[17] Trouillas, P.; Marsal, P.; Siri, D.; Lazzaroni, R.; Duroux, J-L. A DFT study of the reactivity of $\mathrm{OH}$ groupsin quercetin and taxifolin antioxidants: The specificity of the 3-OH site. Food Chem. 2006, 97, 679-688.

[18] Amic, D.; Lucie, B. Bioorganic \& Medicinal Chemistry. 18 (2010) 28.

[19] Zhang, H-Y.; Wang. L-F.; J. Am. Oil Chem. Soc. 79 (2002) 79

[20] Anouar, E.H.; Gierschner, J.; Duroux, J.L.; Trouillas, P. Food Chemistry. 131 (2012) 79.

[21] Szabo, A.; Oslund, N.S. Modern quantum chemistry:Introduction to advanced electronic structure theory, New-York: Dover Publication. (1982).

[22] Leopoldini, M.; Marino, T.; Russo, N.; Toscano, M. Density functional computation of the energetic and spectroscopic parametes of quercetin and its radicals in the gas phase and in solvent, Theoretical Chemistry Accounts. 2004, 111, 210-216.

[23] Parkinson, C.J.; Mayer, P.M.; Radom, L. Assessment of theoretical procedures for the calculation of reliable radical stabilization energies, Journal of the Chemical Society, Perkin Transaction. 1999,11, 2305-2313. 